University of Nebraska - Lincoln

DigitalCommons@University of Nebraska - Lincoln

2010

Detection of the Abnormal Isoform of the Prion Protein Associated With Chronic Wasting Disease in the Optic Pathways of the Brain and Retina of Rocky Mountain Elk (Cervus elaphus nelsoni)

T. R. Spraker

Colorado State University - Fort Collins

Katherine I. O'Rourke

U.S. Department of Agriculture, katherine.orourke@ars.usda.gov

T. Gidlewski

U.S. Department of Agriculture

J. G. Powers

National Park Service

J. J. Greenlee

U.S. Department of Agriculture

See next page for additional authors

Follow this and additional works at: https://digitalcommons.unl.edu/zoonoticspub

Part of the Veterinary Infectious Diseases Commons

Spraker, T. R.; O'Rourke, Katherine I.; Gidlewski, T.; Powers, J. G.; Greenlee, J. J.; and Wild, M. A., "Detection of the Abnormal Isoform of the Prion Protein Associated With Chronic Wasting Disease in the Optic Pathways of the Brain and Retina of Rocky Mountain Elk (Cervus elaphus nelsoni)" (2010). Other Publications in Zoonotics and Wildlife Disease. 153.

https://digitalcommons.unl.edu/zoonoticspub/153

This Article is brought to you for free and open access by the Wildlife Disease and Zoonotics at DigitalCommons@University of Nebraska - Lincoln. It has been accepted for inclusion in Other Publications in Zoonotics and Wildlife Disease by an authorized administrator of DigitalCommons@University of Nebraska - Lincoln. 


\section{Authors}

T. R. Spraker, Katherine I. O'Rourke, T. Gidlewski, J. G. Powers, J. J. Greenlee, and M. A. Wild 


\title{
Detection of the Abnormal Isoform of the Prion Protein Associated With Chronic Wasting Disease in the Optic Pathways of the Brain and Retina of Rocky Mountain Elk (Cervus elaphus nelsoni)
}

Veterinary Pathology 47(3) $536-546$

(C) The American College of

Veterinary Pathologists 2010

Reprints and permission: sagepub.com/journalsPermissions.nav DOI: $10.1177 / 0300985810363702$ http://vet.sagepub.com

(s)

\author{
T. R. Spraker', K. I. O'Rourke ${ }^{2}$, T. Gidlewski ${ }^{3}$, J. G. Powers ${ }^{4}$, \\ J. J. Greenlee ${ }^{5}$, and M. A. Wild ${ }^{4}$
}

\begin{abstract}
Eyes and nuclei of the visual pathways in the brain were examined in 30 Rocky Mountain elk (Cervus elaphus nelsoni) representing 3 genotypes of the prion protein gene PRNP (codon I32: MM, ML, or LL). Tissues were examined for the presence of the abnormal isoform of the prion protein associated with chronic wasting disease (PrPCWD). Nuclei and axonal tracts from a single section of brain stem at the level of the dorsal motor nucleus of the vagus nerve were scored for intensity and distribution of $\mathrm{PrP} C W D$ immunoreactivity and degree of spongiform degeneration. This obex scoring ranged from 0 (elk with no $\operatorname{PrP} \mathrm{PWD}^{\mathrm{CW}}$ the brain stem) to 10 (representing elk in terminal stage of disease). PrPCWD was detected in the retina of 16 of 18 (89\%) elk with an obex score of $>7$. PrPCWD was not detected in the retina of the 3 chronic wasting disease-negative elk and 9 elk with an obex score of $<6$. PrPCWD was found in the nuclei of the visual pathways in the brain before it was found in the retina. Within the retina, $\operatorname{PrP} \mathrm{CWD}^{\mathrm{CW}}$ was first found in the inner plexiform layer, followed by the outer plexiform layer. Intracytoplasmic accumulation of PrPCWD was found in a few neurons in the ganglion cell layer in the PRNP I32ML elk but was a prominent feature in the PRNP 132LL elk. Small aggregates of PrPCWD were present on the inner surface of the outer limiting membrane in PRNP I32LL elk but not in PRNP I32MM or 132ML elk. This study demonstrates PrPCWD accumulation in nuclei of the visual pathways of the brain, followed by $\mathrm{PrP}^{\mathrm{CWD}}$ in the retina.
\end{abstract}

\section{Keywords}

brain, chronic wasting disease, eyes, prion protein, retina, Rocky Mountain elk, visual pathways

Chronic wasting disease (CWD), a transmissible spongiform encephalopathy, has been reported in captive and freeranging cervids. ${ }^{3,32,37,38} \mathrm{An}$ abnormal isoform of the prion protein has been found in cervids with $\mathrm{CWD}\left(\mathrm{PrP}^{\mathrm{CWD}}\right)$, and it can be detected with immunohistochemistry. ${ }^{33} \mathrm{PrP}^{\mathrm{CWD}}$ has been reported in the brain, lymphoid tissues, and other organs (including the retina) in mule deer and white-tailed deer with CWD. ${ }^{9,16,27,32}$ Misfolded prion proteins have been associated with other transmissible spongiform encephalopathies and have been reported in retinas of domestic sheep inoculated with the scrapie agent ${ }^{7,14}$ and in humans with sporadic and variant Creutzfeldt-Jakob disease. ${ }^{10}$ This communication documents the occurrence of $\operatorname{PrP}^{\mathrm{CWD}}$ in the retina, optic nerve, and visual pathways of the brain in Rocky Mountain elk with natural occurring CWD. Disease progression in preclinical elk with natural exposure to CWD was estimated from the intensity and distribution of immunoreactivity and spongiform change in the brain stem at the level of the dorsal motor nucleus of the vagus nerve (obex score). Distribution of $\mathrm{PrP}^{\mathrm{CWD}}$ in the retina and optic pathways was a late-stage event, observed only in elk with relatively high obex scores. Minor variation in the

\footnotetext{
' Colorado State University Diagnostic Laboratory, Fort Collins, Colorado

${ }^{2}$ US Department of Agriculture, Agricultural Research Service, Animal Disease Research Unit, Pullman, Washington

${ }^{3}$ US Department of Agriculture, Animal and Plant Health Inspection Service, Wildlife Services, Fort Collins, Colorado

${ }^{4}$ National Park Service, Biological Resources Management Division, Fort Collins, Colorado

${ }^{5}$ US Department of Agriculture, Agricultural Research Service, National Animal Disease Center, Ames, lowa
}

Corresponding Author:

T. R. Spraker, Colorado State University Diagnostic Laboratory, 300 West Drake Road, College of Veterinary Medicine and Biomedical Sciences, Colorado State University, Fort Collins, CO 80526

Email: terry.spraker@colostate.edu 
distribution pattern of $\mathrm{PrP}^{\mathrm{CWD}}$ in the retina may be associated with a polymorphism at codon 132 of the PRNP gene, a site associated with incubation time in $\mathrm{elk}^{8,23}$ and relative susceptibility and disease expression in humans (human codon $129)$ with sporadic and acquired transmissible spongiform encephalopathies. ${ }^{19}$

\section{Materials and Methods}

Eyes and brain were collected postmortem from 27 Rocky Mountain elk diagnosed with CWD by immunohistochemistry assay of antemortem biopsy samples of rectal mucosalassociated lymphoid tissue $e^{31,34}$ or postmortem assay of brain and lymphoid tissues. ${ }^{33}$ Negative-control elk included 2 ranch-raised elk from a herd free of a history of CWD and 1 free-ranging elk with no detectable $\mathrm{PrP}^{\mathrm{CWD}}$ in brain or lymphoid tissues.

The open reading frame of the $P R N P$ gene was sequenced in all the elk as described. ${ }^{22}$ The previously described coding change at codon 132 was detected; elk were identified as homozygous for the wild-type allele encoding methionine (132MM), homozygous for the alternative allele encoding leucine (132LL), or heterozygous for the alleles (132ML).

Fourteen elk (47\%) were free-ranging adult cows (eleven $132 \mathrm{MM}$, three $132 \mathrm{ML}$ ) originating from north-central Colorado and 11 elk (37\%) originating from captive herds in northern Colorado. The captive group included 8 bulls (seven $132 \mathrm{MM}$, one 132ML) and 3 cows (two 132MM, one 132ML). In addition, two 132LL elk experimentally fed a pooled brain homogenate from two 132ML CWD-positive elk were examined. ${ }^{8,23}$ Both were euthanized at 60 months postinfection.

Following euthanasia, eyes were collected within 1 to 5 minutes from each elk. The globe of each eye was opened via an incision through the sclera just posterior to the limbus, thus increasing exposure of the retina to fixative. Eyes were placed in Davidson's fixative for 3 days. ${ }^{13}$ Brains were collected within 4 hours of death from each elk, hemisectioned, placed in $10 \%$ neutral buffered formalin, and fixed for 1 week. The formalin was changed at least twice for each brain. Sections from each brain were cut at $5 \mu \mathrm{m}$ and immunolabeled as previously described with anti-prion protein monoclonal antibody F99/97.6.1 ${ }^{33}$ (mAb99; Anti-Prion (99), Ventana Medical Systems, Inc, Tucson, AZ) and monoclonal antibody P4 (mAbP4). ${ }^{36}$ The latter binds an epitope at residues 93-99, near the amino terminus of the processed prion protein; the former binds an epitope at residues 220-225, near the carboxyl terminus of the processed prion protein. ${ }^{21}$ Hematoxylin and eosin-stained sections were examined from all sections for spongiform degeneration. ${ }^{29}$

To confirm the CWD status, one section of obex was examined from each elk (ie, brain stem at the level where the fourth ventricle converges into the central canal of the spinal cord); this section contained the dorsal motor nucleus of the vagus nerve (DMNV), medial retropharyngeal lymph node, and palatine tonsil. In addition, the stage of the disease was estimated by scoring the degree of detectable positive chromogen immunoreactivity in the nuclei and white matter tracts, combined with the degree of spongiform degeneration in this section. The evaluated nuclei included the DMNV, area postrema, solitary nucleus, cuneate nucleus, nucleus of the spinal tract of the trigeminal nerve, nucleus ambiguus, reticular formation area/ nucleus, olivary nuclei, medial raphe, and hypoglossal nucleus. ${ }^{39}$ The obex was scored as a progressive increase in intensity of $\mathrm{PrP}^{\mathrm{CWD}}$ immunoreactivity and distribution, essentially as described, ${ }^{30}$ with additional classification criteria based on the intensity of spongiform degeneration and $\mathrm{PrP}^{\mathrm{CWD}}$ in axonal tracts. An obex score of 0 was assigned to elk with no detectable $\operatorname{PrP}^{\mathrm{CWD}}$ in the brain stem. Scoring of samples with detectable $\operatorname{PrP}^{\mathrm{CWD}}$ in the obex ranged from 1, characterized by minimal immunoreactivity of the ventral aspects of the DMNV (Fig. 1), to 10, characterized by all the nuclei and axonal tracts containing a moderate to heavy $\operatorname{PrP}^{\mathrm{CWD}}$ immunoreactivity (Fig. 2). All nuclei had mild to severe spongiform degeneration. Intermediate stages were defined by an increase in immunoreactivity intensity and spongiform degeneration. A detailed description of this scoring system is in preparation.

Eyes from each animal and brain sections of the proposed visual pathways were trimmed and embedded in paraffin blocks. The visual pathways within the brain of elk have not been described; therefore, the visual pathways described in humans were applied. The pathway is assumed to include, in order, retina, optic nerve, optic chiasm, optic tract, lateral geniculate nucleus, optic radiations, and visual cortex of the occipital lobe - all of which were sampled. Impulses leaving the lateral geniculate nucleus also travel to the superior colliculus (sampled) and midbrain tectum; these are primarily reflex. The oculomotor nucleus (sampled), even though not directly a part of the visual pathway, was examined because this nucleus controls multiple functions of the eye, including pupillary size. ${ }^{1,2,26}$ Immunoreactivity intensity was scored as 0 (no labeling detected), 0.5 (trace amounts of chromogen in some areas of the region), 1 (light labeling within the region), 2 (moderate labeling in the region), and 3 (heavy chromogen deposits throughout the region). Elk were grouped by obex score, and the median value was calculated for each group at each anatomic site in the visual pathway.

\section{Results}

\section{Clinical Status and PRNP Genotype of the Test Population}

Of the 27 CWD-positive elk, 20 were nonclinical and 7 showed typical clinical signs of CWD at the time of euthanasia. Clinical signs included behavior changes, mild to moderate aggression when cornered, weight loss, excessive salivation, grinding of the teeth, and emaciation. PRNP genotypes in the 25 naturally infected elk included twenty $132 \mathrm{MM}$ elk $(80 \%)$ and five 132ML elk (20\%), a ratio similar to that observed in the natural population. ${ }^{22,24}$ Elk homozygous for the $132 \mathrm{~L}$ allele are relatively rare in the population; therefore, 2 experimentally 


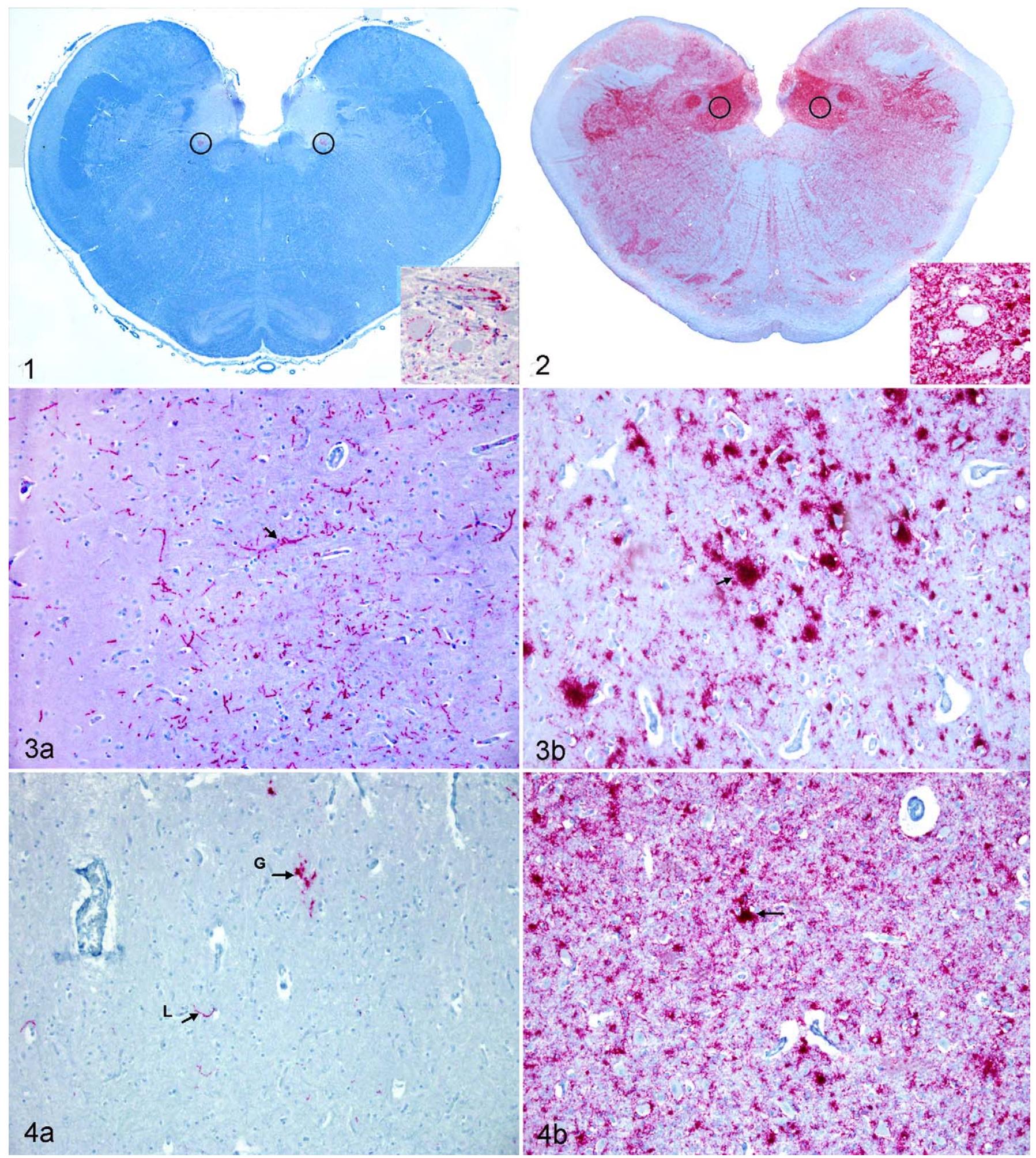

Figure I. Subgross photograph of a cross section of the brain stem at the level of the obex of an elk with an obex score of 2 . Note the scant red granular staining in the ventral aspects of the dorsal motor nucleus of the vagus nerve (circled). Inset: Circled area. Note the minimal degree of red granular PrPCWD staining on the periphery of neurons and within the neuropil of the dorsal motor nucleus of the vagus nerve. Immunohistochemical staining: Anti Prion (99) monoclonal antibody 99, streptavidin-alkaline-phosphatase method. Hematoxylin/bluing counterstain. PrPCWD, prion protein associated with chronic wasting disease. Figure 2. Subgross photograph of a cross section of the obex of an elk with an obex score of 10. Note the extensive red granular staining in all the nuclear areas, with less staining in axonal tracts. Inset: Circled area within the vagus nucleus. Note the extensive red granular PrPCWD staining within the neuropil and on the periphery of neurons throughout 
infected animals described in previous studies ${ }^{8,23}$ were added to this study.

\section{Obex Scores of Preclinical and Clinically Affected Elk}

The obex was scored in all 30 elk based on the distribution and intensity of immunoreactivity combined with the degree of spongiform degeneration. Neither $\operatorname{PrP}^{\mathrm{CWD}}$ detected by immunoreactivity nor spongiform degeneration was observed in the brain stem from the 3 negative control elk. Of the twenty 132MM CWD-positive elk, obex scores were as follows: one 1 , two $2 \mathrm{~s}$, one 3 , one 4 , one 6 , three $7 \mathrm{~s}$, three $8 \mathrm{~s}$, three $9 \mathrm{~s}$, and five 10s (Table 1). Of the five 132ML-positive elk, the obex scores were as follows, one of each: 4, 5, 6, 8, 10. One 132LL elk had an obex score of 8 and the other, a score of 9 . Elk with obex scores of $<9$ were clinically normal except for 2 elk, 1 with a score of 8 and the other, a score of 9; both these elk had pneumonia at the time of necropsy.

\section{PrP CWD in the Brain and Visual Pathway of Elk at Different Stages of CWD}

Immunoreactivity of the visual pathway was scored at 9 neuroanatomic locations in samples from elk with obex scores ranging from 1 to 10 . Table 2 shows the median scores for each location in relation to the obex score. The earliest sites of $\mathrm{PrP}^{\mathrm{CWD}}$ immunoreactivity were the visual cortex (1 of 2$)$ and superior colliculus ( 2 of 2 ) in the brain of elk with an obex score of 2. Heaviest $\mathrm{PrP}^{\mathrm{CWD}}$ immunoreactivity was observed in the superior colliculus, oculomotor nucleus, visual cortex, lateral geniculate nucleus, and retina in elk with an obex score of 9 or 10. At each location, visual pathway scores were higher in elk with higher obex scores. $\operatorname{PrP}^{\mathrm{CWD}}$ immunoreactivity was detected in the retina of elk with obex scores of 7 or higher. The character and location of the $\mathrm{PrP}^{\mathrm{CWD}}$ immunoreactivity varied with obex score and genotype, as follows.

Obex score $=0$. Neither histological lesions nor $\mathrm{PrP}^{\mathrm{CWD}}$ immunoreactivity was detected in obex, brain, lymphoid tissues, or sections of the visual pathway including the eye of the 3 control elk.

Obex score $=I$. One 132MM elk had an obex score of 1 . This elk had no detectable $\operatorname{PrP}^{\mathrm{CWD}}$ immunoreactivity in the visual pathways of the brain or retina. Spongiform degeneration was not found in any of the nuclei of the visual pathway. Histological lesions were not detected in any of the layers of the retina.

Obex score $=2$. Two 132MM elk had an obex score of 2 . $\mathrm{PrP}^{\mathrm{CWD}}$ immunoreactivity was detected in the visual cortex of 1 elk and in the superior colliculus in both elk. The pattern of $\mathrm{PrP}^{\mathrm{CWD}}$ immunoreactivity was considered to be trace and primarily linear. Evidence of spongiform degeneration was not found in any of the nuclei of the visual pathway. Histological lesions or $\mathrm{PrP}^{\mathrm{CWD}}$ immunoreactivity was not detected in any of the layers of the retina.

Obex score $=3$. One $132 \mathrm{MM}$ elk had an obex score of 3. $\mathrm{PrP}^{\mathrm{CWD}}$ immunoreactivity was detected in the visual cortex in this elk (Fig. 3A). The pattern of $\operatorname{PrP}^{\mathrm{CWD}}$ immunoreactivity was considered to be mild and primarily linear. No evidence of spongiform degeneration was found in any of the nuclei of the visual pathway. Histological lesions or $\mathrm{PrP}^{\mathrm{CWD}}$ immunoreactivity was not detected in any of the layers of the retina in this elk.

Obex score $=4$. Two elk (one 132MM and one 132ML) had an obex score of 4 . $\mathrm{PrP}^{\mathrm{CWD}}$ immunoreactivity was detected in the lateral geniculate nucleus, the oculomotor nucleus, superior colliculus, and visual cortex in the $132 \mathrm{MM}$ elk but only in the visual cortex in the 132ML elk. The pattern of $\operatorname{PrP}^{\mathrm{CWD}}$ immunoreactivity was primarily linear, but coarse granules of chromogen were found in the visual cortex and lateral geniculate nucleus in the 132MM elk and in the superior colliculus in both elk. Spongiform degeneration was confined to the DMNV in both elk and not found in nuclei of the visual pathway. Histological lesions or PrP $\mathrm{P}^{\mathrm{CWD}}$ immunoreactivity was not detected in any of the layers of the retina in these 2 elk.

Obex score $=5$. One elk (132ML) had an obex score of 5 . $\mathrm{PrP}^{\mathrm{CWD}}$ immunoreactivity was detected in the lateral geniculate nucleus, superior colliculus, visual cortex, and oculomotor nucleus in this elk. Both linear and granular patterns were found in this stage, but the linear pattern was more prominent. Spongiform degeneration was confined to the obex and not found in nuclei of the visual pathway. Histological lesions or $\mathrm{PrP}^{\mathrm{CWD}}$ immunoreactivity was not detected in any of the layers of the retina in this elk.

Figure 2. (continued) the dorsal motor nucleus of the vagus nerve. Immunohistochemical staining: Anti Prion (99) monoclonal antibody 99, streptavidin-alkaline-phosphatase method. Hematoxylin/bluing counterstain. PrPCWD, prion protein associated with chronic wasting disease. Figure 3. Photomicrograph of the visual cortex from two I32MM CWD-positive elk. $A$, an elk with an obex score of 3. B, an elk with an obex score of 10. Note the linear staining (arrow) of $\operatorname{PrPCWD}(A)$ compared to the course granular staining (arrow) with plaque formation (B). Immunohistochemical staining: Anti Prion (99) monoclonal antibody 99, streptavidin-alkaline-phosphatase method. Hematoxylin/bluing counterstain. I32MM: codon 132, elk identified as homozygous for the wild-type allele encoding methionine. CWD, chronic wasting disease; PrPCWD, prion protein associated with chronic wasting disease. Figure 4. Photomicrograph of the superior colliculus from two I32MM positive CWD elk. A, an elk with an obex score of 6 . Note the minimal amount of linear $(L)$ and granular $(G)$ staining of $\operatorname{PrP}{ }^{C W D}$. B, an elk with an obex score of 10. Note the lack of linear staining with the abundance of granular staining and plaque formation (arrow). Immunohistochemical staining: Anti Prion (99) monoclonal antibody 99, streptavidin-alkaline-phosphatase method. Hematoxylin/bluing counterstain. 32MM: codon I32, elk identified as homozygous for the wild-type allele encoding methionine. CWD, chronic wasting disease; PrPCWD, prion protein associated with chronic wasting disease. 
Table I. Rocky Mountain Elk in Which Eyes Were Collected For Examination

\begin{tabular}{|c|c|c|c|c|c|}
\hline Elk No. & PRNP Genotype ${ }^{\mathrm{a}}$ & Source $^{b}$ & Clinical Signs & Obex Score ${ }^{c}$ & $\operatorname{PrP}^{C W D}$ in Retina ${ }^{d}$ \\
\hline T78-6II0 & MM & $\mathrm{F}$ & No & I & $\mathrm{N}$ \\
\hline T78-6I2I & $M M$ & $\mathrm{~F}$ & No & 2 & $\mathrm{~N}$ \\
\hline T78-6473 & $M M$ & $\mathrm{R}$ & No & 3 & $\mathrm{~N}$ \\
\hline T78-6054 & $M L$ & $\mathrm{~F}$ & No & 4 & $N$ \\
\hline T78-607I & $M M$ & $\mathrm{~F}$ & No & 4 & $\mathrm{~N}$ \\
\hline T78-6I36 & $M M$ & $\mathrm{~F}$ & No & 6 & $\mathrm{~N}$ \\
\hline T78-6070 & MM & $\mathrm{F}$ & No & 7 & $N$ \\
\hline T78-6073 & $M M$ & $\mathrm{~F}$ & No & 7 & $P$ \\
\hline T78-6098 & $M M$ & $\mathrm{~F}$ & No & 7 & $P$ \\
\hline T78-6055 & $M M$ & $\mathrm{~F}$ & No & 8 & $N$ \\
\hline T67-6540 & $M M$ & $\mathrm{R}$ & No & 8 & $P$ \\
\hline T67-44I2 & LL & $E$ & Yes & 9 & $P$ \\
\hline T78-1987 & $M M$ & $\mathrm{~F}$ & No & 9 & $P$ \\
\hline T67-654I & $M M$ & $\mathrm{R}$ & No & 9 & $P$ \\
\hline T78-6474 & $M M$ & $\mathrm{R}$ & Yes & 10 & $P$ \\
\hline T56-7353 & $M M$ & $\mathrm{R}$ & Yes & 10 & $P$ \\
\hline T56-|82| & MM & $\mathrm{R}$ & No & 10 & $P$ \\
\hline T45-7445 & $M L$ & $\mathrm{R}$ & Yes & 10 & $P$ \\
\hline T78-0368 & $M M$ & $\mathrm{~F}$ & Yes & 10 & $P$ \\
\hline T89-3530 & $M M$ & $\mathrm{R}$ & Yes & 10 & $P$ \\
\hline
\end{tabular}

n, 27.

a Deduced amino acid at residue 132 of the PRNP gene. $M$, methionine; $L$, leucine.

${ }^{b} \mathrm{R}$, ranch-raised elk; $F$, free-ranging elk; $E$, experimental oral exposure.

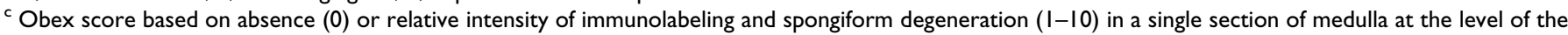
dorsal motor nucleus of the vagus.

${ }^{\mathrm{d}} \mathrm{PrP} \mathrm{PWD}^{\mathrm{CWD}}$, prion protein associated with chronic wasting disease. Immunolabeling of the retina: $\mathrm{P}$, elk with; $\mathrm{N}$, elk without.

Table 2. Median PrP ${ }^{C W D}$ Immunoreactivity Intensity Scores of Rocky Mountain Elk With Disease Progression as Estimated From Obex Scores (Number of Elk Affected)

\begin{tabular}{|c|c|c|c|c|c|c|c|c|c|c|}
\hline $\begin{array}{l}\text { Obex } \\
\text { Score }\end{array}$ & $\begin{array}{l}\text { No. } \\
\text { Elk }\end{array}$ & Retina & $\begin{array}{l}\text { Optic } \\
\text { Nerve }\end{array}$ & $\begin{array}{l}\text { Optic } \\
\text { Chiasm }\end{array}$ & $\begin{array}{l}\text { Optic } \\
\text { Tract }\end{array}$ & $\begin{array}{l}\text { Lateral Geniculate } \\
\text { Nucleus }\end{array}$ & $\begin{array}{l}\text { Optic } \\
\text { Radiations }\end{array}$ & $\begin{array}{l}\text { Visual } \\
\text { Cortex }\end{array}$ & $\begin{array}{l}\text { Oculomotor } \\
\text { Nucleus }\end{array}$ & $\begin{array}{l}\text { Superior } \\
\text { Colliculus }\end{array}$ \\
\hline I & I & 0 & 0 & 0 & 0 & 0 & 0 & 0 & 0 & 0 \\
\hline 3 & I & 0 & 0 & 0 & 0 & 0 & 0 & I.0 (I) & 0 & 0 \\
\hline 4 & 2 & 0 & 0 & 0 & 0 & $0.5(I)$ & 0 & $\mathrm{I} .0(2)$ & $0.5(I)$ & $0.5(I)$ \\
\hline 5 & 1 & 0 & 0 & 0 & 0 & $1.0(1)$ & 0 & $1.0(I)$ & $2.0(I)$ & $1.0(1)$ \\
\hline 8 & 5 & $1.4(4)$ & $0.9(4)$ & $0.7(4)$ & 0.7 (4) & $1.9(5)$ & $1.6(5)$ & $2.0(5)$ & $2.0(5)$ & $2.2(5)$ \\
\hline 9 & 4 & $2.8(4)$ & $1.3(3)$ & $0.6(3)$ & $0.9(4)$ & $2.0(4)$ & $1.8(4)$ & I.5 (4) & $2.3(4)$ & $2.3(4)$ \\
\hline 10 & 6 & $2.5(6)$ & $1.5(6)$ & $2.7(3)^{a}$ & $1.7(6)$ & $3.0(6)$ & $2.0(6)$ & $3.0(6)$ & $3.0(6)$ & $3.0(6)$ \\
\hline
\end{tabular}

PrPCWD, prion protein associated with chronic wasting disease. Immunoreactivity in the retina was not observed until an obex score of $>7$ was obtained. Immunoreactivity intensity was scored as 0 (no labeling detected), 0.5 (trace amounts of chromogen in some areas of the region), I (light labeling within the region), 2 (moderate labeling in the region), and 3 (heavy chromogen deposits throughout the region). The number in parentheses is the number of elk in each category affected.

${ }^{\text {a }}$ The optic chiasm was collected in only 3 of these 6 elk.

Obex score $=6$. Two elk (one 132MM and one 132ML) had an obex score of $6 . \mathrm{PrP}^{\mathrm{CWD}}$ immunoreactivity was detected in the superior colliculus (Fig. 4A), visual cortex, and oculomotor nucleus in the $132 \mathrm{ML}$ elk. $\operatorname{PrP}^{\mathrm{CWD}}$ immunoreactivity was detected in the lateral geniculate nucleus, superior colliculus, visual cortex, and oculomotor nucleus in the 132MM elk. Both 

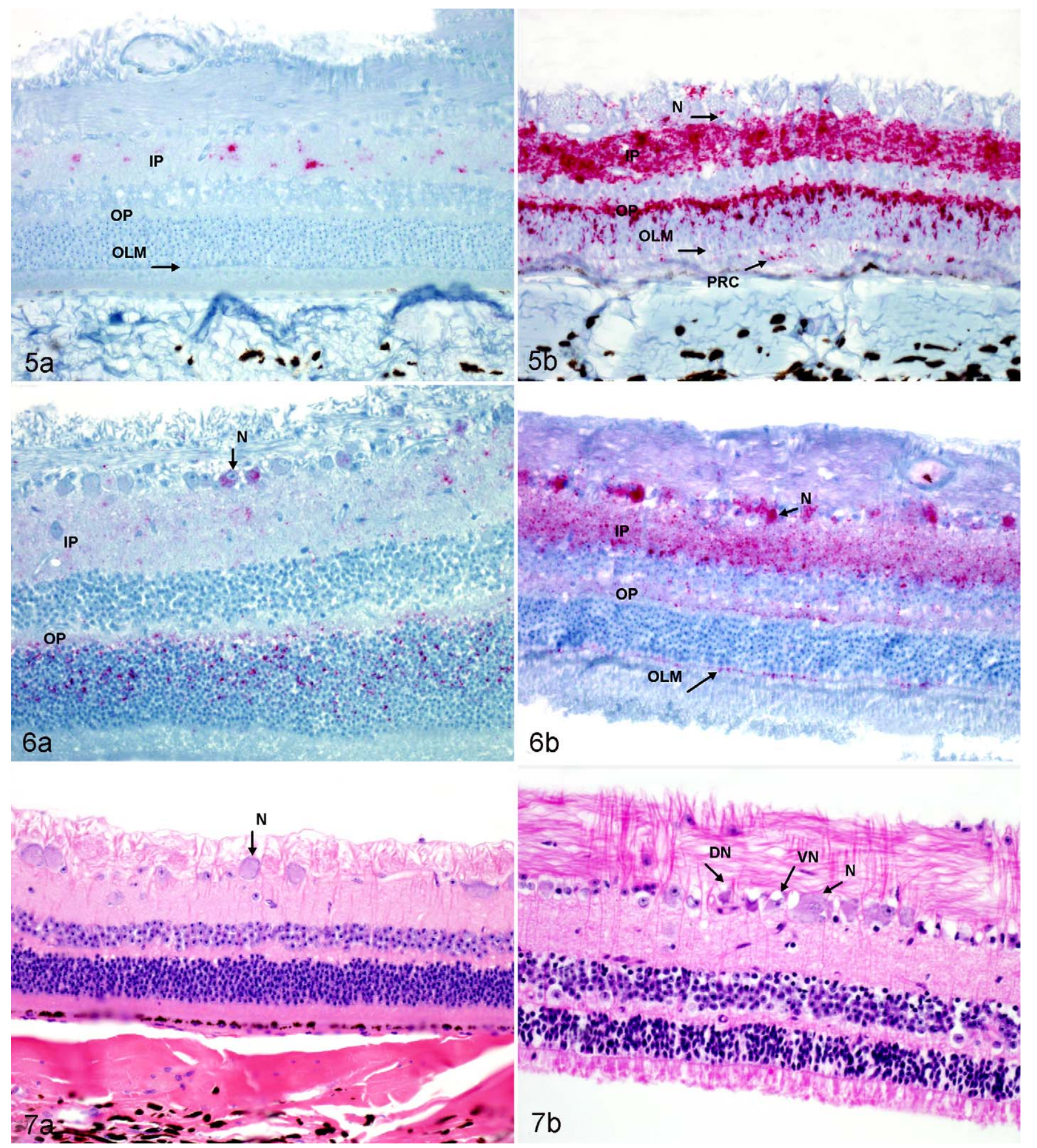

Figure 5. Photomicrograph of the retina in 2 CWD-positive I32MM elk. A, an elk with an obex score of 7. Note the minimal bright red granular chromogen deposition in the inner plexiform (IP) layer and the absence of staining in the outer plexiform (OP) and outer limiting membrane (OLM) layers. B, an elk with an obex score of 9 . Note the heavy staining in the IP and OP layers, with less staining in other layers; the absences of intracytoplasmic staining of the neurons $(N)$ of the ganglion cell layer and the lack of accumulation of small aggregates of chromogen on the inner surface of the OLM in both elk; and the granular staining in the layer of photoreceptor cells (PRC). Immunohistochemical staining: Anti Prion (99), monoclonal antibody 99, streptavidin-alkaline-phosphatase method. Hematoxylin/bluing counterstain. I32MM: codon 132, elk identified as homozygous for the wild-type allele encoding methionine. CWD, chronic wasting disease. Figure 6. Photomicrograph of the retina of a CWD-positive I32ML Rocky Mountain elk with an obex score of I0 (A) and a I32LL elk with an 
linear and granular patterns were found in these elk, but the linear pattern was more prominent. Spongiform degeneration was confined to the obex and not found in nuclei of the visual pathway. $\mathrm{PrP}^{\mathrm{CWD}}$ immunoreactivity or histological lesions were not detected in any layer of retina in these 2 elk.

Obex score $=7$. Three elk (132MM) had an obex score of 7 . $\mathrm{PrP}^{\mathrm{CWD}}$ immunoreactivity was detected in the optic tracts of 1 elk; in the retina, lateral geniculate nucleus, and optic radiations of 2; and in the visual cortex, oculomotor nucleus, and superior colliculus of all 3 . The patterns of $\mathrm{PrP}^{\mathrm{CWD}}$ immunoreactivity were predominately granular, but areas of linear staining were still found. An increased number of plaques of $\mathrm{PrP}^{\mathrm{CWD}}$ immunoreactivity were found in all visual pathways in the brain. In most areas, these plaques appeared to be surrounding and filling the cytoplasm of astrocytes. Mild spongiform degeneration was found within ocular motor nucleus and superior colliculus. $\operatorname{PrP}^{\mathrm{CWD}}$ immunoreactivity was detected in the inner plexiform layer of the retina in one (Fig. 5A) and in the inner and outer plexiform layer in the other. The pattern of $\mathrm{PrP}^{\mathrm{CWD}}$ immunoreactivity in the retina of the $132 \mathrm{MM}$ elk was characterized by light red granular chromogen staining that was first detected in the inner plexiform layer.

Obex score $=8$. Five elk (three 132MM, one 132ML, and one 132LL) had an obex score of $8 . \mathrm{PrP}^{\mathrm{CWD}}$ immunoreactivity was detected in the retina of two 132MM elk and the 132ML and $132 \mathrm{LL}$ elk. $\mathrm{PrP}^{\mathrm{CWD}}$ immunoreactivity was detected in the optic nerve, optic chiasm, and optic tracts in two 132MM elk. $\mathrm{PrP}^{\mathrm{CWD}}$ immunoreactivity was detected in the lateral geniculate nucleus, optic radiations, visual cortex, oculomotor nucleus, and superior colliculus in all 5 elk. The pattern of immunoreactivity in these elk was of the coarse granular pattern with an increased number of plaques. Linear staining was minimal. Mild to moderate spongiform degeneration was found in the nuclei of the visual pathways within the brain. $\operatorname{PrP}^{\mathrm{CWD}}$ immunoreactivity was detected in multiple layers of the retina in all 5 elk. All layers had some degree of $\operatorname{PrP}^{\mathrm{CWD}}$ immunoreactivity, except the outer limiting membrane and the pigmented epithelium. Layers of the retina with the most intense $\mathrm{PrP}^{\mathrm{CWD}}$ immunoreactivity were the inner and outer plexiform layers. Intracytoplasmic $\mathrm{PrP}^{\mathrm{CWD}}$ immunoreactivity within neurons of the ganglion cell layer was present in the 132ML elk but was a prominent feature in the 132LL elk (Fig. 6A, 6B).
Intracytoplasmic $\mathrm{PrP}^{\mathrm{CWD}}$ immunoreactivity within neurons of the ganglion cell layer was not present in the 132MM elk. Small aggregates of $\mathrm{PrP}^{\mathrm{CWD}}$ immunoreactivity were present on the inner surface of the outer limiting membrane in $132 \mathrm{LL}$ elk but not in $132 \mathrm{MM}$ or $132 \mathrm{ML}$ elk.

Obex score $=9-10$. Four (three 132MM and one 132LL) elk had an obex score of 9 , and 6 had an obex score of 10 (five $132 \mathrm{MM}$ and one 132ML). $\mathrm{PrP}^{\mathrm{CWD}}$ immunoreactivity was found in all the neuroanatomical visual pathways in the brain (Figs. 3B, 4B). The patterns of $\operatorname{PrP}^{\mathrm{CWD}}$ immunoreactivity were similar to those described in elk with an obex score of 8 . Linear staining was rare. Mild to severe spongiform degeneration was found in the nuclei of the visual pathways in all these elk. $\mathrm{PrP}^{\mathrm{CWD}}$ immunoreactivity was found in all layers of the retina except the outer limiting membrane and the pigmented epithelial layers in the $132 \mathrm{MM}$ elk. Small aggregates of $\mathrm{PrP}^{\mathrm{CWD}}$ immunoreactivity were present on the inner surface of the outer limiting membrane in 132LL elk but not in the 132MM elk (Fig. 5B). A few ganglia of the retina showed evidence of central chromatolysis, vacuolation, and necrosis (Fig. 7A, 7B) but with slightly more frequency in the elk with a score of 10 . The overall degree of spongiform degeneration of the retina was minimal in all genotypes.

\section{Epitope Mapping With Amino Terminal Antibody P4 and Carboxyl Terminal Antibody 99}

The intensity and location of $\mathrm{PrP}^{\mathrm{CWD}}$ immunoreactivity observed with mAbP4 in the brain and retinal sections were similar to those of the brain and retinal sections in the $132 \mathrm{MM}$ and 132ML elk stained with mAb99. Immunoreactivity with mAbP4 was identical in character and pattern to that observed with mAb99 except in one location in the 132LL elk. The accumulation of red chromogen granules on the inner surface of the outer limiting membrane as seen in the 132LL elk immunostained with mAb99 was not observed with mAbP4.

\section{Lack of PrP ${ }^{C W D}$ Immunoreactivity in Other Structures in the Eye}

$\mathrm{PrP}^{\mathrm{CWD}}$ immunoreactivity or histological lesions were not found in the lens, ciliary body, iris, cornea, or sclera in any of the 3 genotypes of the 27 CWD-positive elk.

Figure 6. (continued). obex score of 9 (B). Both elk were showing clinical signs when euthanized. Note the reduced amount of red chromogen deposition of $\mathrm{PrPCWD}$ in the inner plexiform (IP) and outer plexiform (OP) layers of the retina as compared to that of the I32MM elk. Note also the heavy intracytoplasmic staining of the neurons $(\mathrm{N})$ of the ganglion cell layer and the accumulation of small aggregates of chromogen on the inner surface of the outer limiting membrane (OLM) in the I32LL elk as compared to the I32 ML elk. Immunohistochemical staining: Anti Prion (99), monoclonal antibody 99, streptavidin-alkaline-phosphatase method. Hematoxylin/bluing counterstain. I32MM: codon 132, elk identified as homozygous for the wild-type allele encoding methionine; I32LL: codon I32, elk identified as homozygous for the alternative allele encoding leucine; I32ML: codon I32, elk identified as heterozygous for the wild-type allele encoding methionine and for the alternative allele encoding leucine. CWD, chronic wasting disease; PrPCWD, prion protein associated with chronic wasting disease. Figure 7. Photomicrograph of the retina from a CWD-positive 132ML Rocky Mountain elk with an obex score of I0. A, early lesions characterized by central chromolysis of neurons $(\mathrm{N})$ of the ganglia cell layer. $B$, retina of the same elk. Note unaffected $(\mathrm{N})$, vacuolated $(\mathrm{V})$, and dead neurons (DN) within the ganglia cell layer. HE. I32ML: codon 132, elk identified as heterozygous for the wild-type allele encoding methionine and for the alternative allele encoding leucine. CWD, chronic wasting disease. 


\section{Discussion}

The degree of PrP ${ }^{\mathrm{CWD}}$ immunoreactivity and spongiform encephalopathy is thought to correlate with the duration of disease. Researchers have suggested that for mule deer and white-tailed deer, the more detectable $\mathrm{PrP}^{\mathrm{CWD}}$ and severity of spongiform degeneration in neural tissues, the longer the animal has been incubating the disease ${ }^{6,16,35}$; however, this relationship has not yet been delineated in elk. Neither the pathogenesis nor the dissemination of the agent through the host is well defined in Rocky Mountain elk. In this study, we examined the presumed progression of $\mathrm{PrP}^{\mathrm{CWD}}$ dissemination along the visual pathway. Detection of $\mathrm{PrP}^{\mathrm{CWD}}$ immunoreactivity in the retina has been reported in mule deer ${ }^{35}$ and white-tailed deer ${ }^{16}$ with CWD, ovine scrapie, ${ }^{4,12}$ and bovine spongiform encephalopathy, ${ }^{7}$ but the pathway and kinetics of prion protein accumulation are not reported. Data from this study demonstrated that detectable $\mathrm{PrP}^{\mathrm{CWD}}$ immunoreactivity first accumulated in the visual pathways of the brain, before the retina. Elk with an obex score of $<6$ had no evidence of $\mathrm{PrP}^{\mathrm{CWD}}$ immunoreactivity in the optic nerve or retina but did have $\operatorname{PrP}^{\mathrm{CWD}}$ immunoreactivity in neural regions of the visual pathway in the brain. The first nuclear area where $\mathrm{PrP}^{\mathrm{CWD}}$ immunoreactivity was detected was in the superior colliculus, followed by the visual cortex (obex score of 2). Next PrP ${ }^{\mathrm{CWD}}$ immunoreactivity was detected in the lateral geniculate nucleus and oculomotor nucleus (obex scores of 3 to 6). PrP $\mathrm{P}^{\mathrm{CWD}}$ immunoreactivity was first detected in the retina in elk with an obex score of 7. At this time, $\mathrm{PrP}^{\mathrm{CWD}}$ immunoreactivity was beginning to accumulate to detectable levels in the axonal tracts of the visual pathway (the optic radiations, optic tracts, optic chiasm, and optic nerve). Elk with an obex score of 7 usually had $\mathrm{PrP}^{\mathrm{CWD}}$ immunoreactivity in the optic nerve and retina but at much lower intensity as compared to that of the more advanced elk with an obex score of 9 or 10 .

Elk with an obex score of $<5$ were thought to be in relatively early stages of disease; elk with an obex score of 6 to 7 were thought to be in the midstage of disease; and elk with an obex grade of $>8$ were in a more advanced stage. Clinical signs were primarily observed in elk with an obex score of 10; however, 2 elk (one with a score of 8 and the other, a score of 9) did show mild signs, but both had pneumonia at the time of necropsy. In addition to differences in distribution, the immunoreactivity characteristics of $\operatorname{PrP}^{\mathrm{CWD}}$ were different as the disease progressed. The pattern of $\operatorname{PrP}^{\mathrm{CWD}}$ immunoreactivity in the brain in early cases was mostly linear, apparently composed of small granular particles of $\mathrm{PrP}^{\mathrm{CWD}}$ immunoreactivity attached to the periphery of axons or dendrites. The pattern of $\mathrm{PrP}^{\mathrm{CWD}}$ immunoreactivity in later stages of disease was more granular, including plaque formation.

Retina had detectable PrP ${ }^{C W D}$ immunoreactivity in elk with an obex score of $>7$. Prion was first detected in the inner plexiform layer of the retina, then the inner and outer plexiform layers. The prion then spread throughout the remaining retinal layers, sparing the pigmented epithelial layer. In domestic sheep with scrapie, the inner plexiform layer appears to be affected first; then, as the disease progresses, the outer plexiform layer accumulates $\operatorname{PrP}^{\mathrm{Sc}}$ (abnormal prion protein associated with spongiform encephalopathy). ${ }^{7}$ Further evidence suggests that as $\mathrm{PrP}^{\mathrm{Sc}}$ accumulates, there are morphologic changes in retinal ganglion cells, rod bipolar cells, and Müller glia that are associated with functional abnormalities. ${ }^{28}$ The spread of $\mathrm{PrP}^{\mathrm{CWD}}$ in the retina of elk may be similar to that of sheep.

The amino acid sequence of the PRNP gene at codon 132 plays a role during the incubation period of elk developing CWD. The 132MM genotype is the most common in freeranging and captive elk, and it is associated with an estimated incubation period of approximately 2.5 years. The $132 \mathrm{ML}$ genotype is not uncommon in captive and free-ranging elk. ${ }^{24} \mathrm{CWD}$ was identified in this genotype at a frequency in proportion to its abundance in the entire sampled population in a recent study. ${ }^{24}$ The experimental incubation period in elk of this genotype was approximately 3.5 years. Finally, 132LL elk are rare in free-ranging and captive elk $(<4 \%)$ and have an experimental incubation period of approximately 5 to 6 years or longer. ${ }^{8,22}$ The elk in this study (except for the two 132LL elk) had been incubating the disease for an unknown period, and the number of times these elk were naturally exposed was not known.

There were 2 patterns of $\mathrm{PrP}^{\mathrm{CWD}}$ immunoreactivity in the retinal layers among the 132MM, 132ML, and 132LL elk. Intracytoplasmic accumulation of $\mathrm{PrP}^{\mathrm{CWD}}$ immunoreactivity within neurons of the ganglion cell layer of the retina was not found in the 132MM elk, but a few neurons with intracytoplasmic $\operatorname{PrP}^{\mathrm{CWD}}$ immunoreactivity were detected in the $132 \mathrm{ML}$ elk. Intracytoplasmic $\mathrm{PrP}^{\mathrm{CWD}}$ immunoreactivity granules within neurons within the ganglion cell layer were a prominent feature in the 132LL elk. This pattern was identical with the mAb99 and mAbP4. It also appeared that even though the overall severity of retinal degeneration was minimal, it was nearly nonexistent in the 132MM elk and only sporadically observed in the $132 \mathrm{ML}$ and $132 \mathrm{LL}$ elk. In mouse models, retinal degeneration was noted in mice expressing $\operatorname{PrP}^{\mathrm{c}}$ (the normal cellular isoform of the prion protein) in astrocytic, microglial, and neuronal cells in the retina but not in mice expressing $\mathrm{PrP}^{\mathrm{c}}$ solely in neurons, thereby suggesting that microglial/astrocytic prion protein expression may be required for scrapie-induced retinal damage. ${ }^{17,18}$ In regard to the elk in this study with naturally occurring CWD, data suggest that the lack of intraneuronal $\mathrm{PrP}^{\mathrm{CWD}}$ immunoreactivity in the $132 \mathrm{MM}$ elk indicates minimal neuronal $\operatorname{PrP}^{\mathrm{C}}$ expression. However, if leucine is incorporated into the $P R N P$ gene, then neuronal $\operatorname{PrP}^{\mathrm{C}}$ expression is increased and, therefore, $\operatorname{PrP}^{\mathrm{CWD}}$. Likewise, the 132LL genotype may be associated with higher neuronal $\operatorname{PrP}^{\mathrm{C}}$ expression.

The second difference was the detection of small aggregates of $\mathrm{PrP}^{\mathrm{CWD}}$ located on the inner surface of the outer limiting membrane in 132LL elk but not in 132MM or 132ML elk. This pattern was observed with mAb99 but not with mAbP4. The outer limiting membrane (or external limiting membrane) is not actually a membrane but a series of junctional complexes between the photoreceptor cells and the Müller cells. The outer limiting membrane is formed by the distal ends of the Müller cells that attach to the photoreceptor cells by zonula 
adherens-type junctions. The filamentous material associated with these intercellular zonula adherens junctions with light microscopy appears to be a membrane. ${ }^{5,15}$ This $\mathrm{PrP}^{\mathrm{CWD}}$ immunoreactivity at the inner surface of the outer limiting membrane suggests that this junction can impede movement of $\operatorname{PrP}^{\mathrm{CWD}}$ to some degree in the 132LL elk but not in the 132MM and $132 \mathrm{ML}$ elk. This may reflect a functional difference between the Müller cells of $132 \mathrm{MM}$ and $132 \mathrm{ML}$ elk and those of the 132LL elk.

Further epitope mapping with antibodies specific for the amino and carboxyl termini of the processed prion protein will be needed to demonstrate a difference in intracellular processing of abnormal $\mathrm{PrP}^{\mathrm{CWD}}$ in tissues of the visual pathway in 132LL elk. We have reported a novel proteinase K cleavage site in $\mathrm{PrP}^{\mathrm{CWD}}$ extracted from brain homogenate from 132LL elk. ${ }^{23}$ In this study, we demonstrate the novel processing in vivo in ganglia of the retina. The reason for these differences was not determined, but it may relate to the mechanisms by which the leucine plays a role in the metabolism or expression of $\operatorname{PrP}^{\mathrm{CWD}}$ or $\operatorname{PrP}^{\mathrm{C}}$ within ganglia and Müller cells.

Data from this study suggest that the retina of elk may be affected in the latter stages of CWD, as similar to the findings of white-tailed deer in which $\operatorname{PrP}^{\mathrm{CWD}}$ was detected in only 4 of 63 CWD-positive white-tailed deer; all 4 white-tailed deer were in advanced disease based on obex scoring. ${ }^{16}$

Prions in the nervous system have been found to localize in the presynaptic junctions in the brain, thereby suggesting that prions may have a function at the synaptic junctions in humans suffering with sporadic and variant Creutzfeldt-Jakob disease. ${ }^{11,20}$ This may explain why the inner and outer plexiform layers of the retina were affected first and had most of the detectable $\mathrm{PrP}^{\mathrm{CWD}}$ immunoreactivity. In domestic sheep, $\operatorname{PrP}^{\mathrm{Sc}}$ has been reported to be heavily concentrated in the synaptic layers of the retina (inner and outer plexiform layers). ${ }^{7,28}$

In the terminal stages of CWD, there is heavy immunoreactivity in neuronal regions of the brain and retina but low immunoreactivity in such regions the optic nerve, optic chiasm, optic tract, and optic radiations. This finding may be due to the lack of synaptic junctions in these predominately large axonal tracts; therefore, these regions would not produce as much $\operatorname{PrP}^{\mathrm{C}}$ and, as such, not support as much $\mathrm{PrP}^{\mathrm{CWD}}$ production or accumulation.

Literature describing clinical signs of CWD has not mentioned visual impairment. ${ }^{32,37,38}$ Elk in terminal stages of CWD often appear to see movement, but if one walks slowly or does not move quickly near an affected elk, the elk does not seem to pay much attention (personal observations, T.R.S.). This behavior has been attributed to lesions in the central nervous system rather than in the eye. The literature does suggest that abnormal prion alters localization of synaptic proteins. ${ }^{25}$ Contributing to this behavior, by causing visual impairment in elk in the latter stages of CWD, is the accumulation of $\mathrm{PrP}^{\mathrm{CWD}}$ within the retina-especially in the inner and outer plexiform layerswith neuronal degeneration of the neurons of the ganglia cell layer, as well as $\operatorname{PrP}^{\mathrm{CWD}}$ accumulation and spongiform degeneration of the nuclei of the visual pathways within the brain.

\section{Acknowledgements}

We would like to thank the owners of the ranch-raised elk (Dennis and Stephanie White, Velvet Ridge Ranch, Fort Collins, CO, and two anonymous owners) for allowing us to do rectal biopsies on their elk and, if positive cases were found, euthanizing and necropsying the suspected positive elk. We would like to thank the National Park Service (Rocky Mountain National Park, Estes Park, CO) for allowing us to perform rectal biopsies on elk and allowing us to necropsy positive elk. We wish to thank Scott Ratchford for collecting the eyes from the free-ranging elk. We wish to thank Vicki Jameson, Tracy Nichols, Chrystal Meyerett, Tara Ruby, Amy Graham, Danielle Lagana, and David Walter for assisting in the necropsies of these elk. We wish to thank Bob Zink, Todd Bass, and Bruce Cummins for cutting and staining the tissues. We would like to thank Linda Hamburg and Desiree Lesiak for genotyping these elk. We greatly appreciate the help from Jay Oaks and Charlie Kerlee with the photomicrografts. This project was partially funded by National Park Service project No. CSURM-98, Cooperative Agreement No. H1200040001, task order No. 123400070064; US Department of Agriculture, Agricultural Research Service, Cooperative Agreement No. 58-5348-8-275, project No. 5348-32000-026-105; and Colorado State University Diagnostic Laboratory, College of Veterinary Medicine and Biomedical Sciences, Colorado State University, Fort Collins, CO.

\section{Declaration of Conflicting Interests}

The authors declared that they had no conflicts of interest with respect to their authorship or the publication of this article.

\section{Financial Disclosure/Funding}

The authors declared that they received no financial support for their research and/or authorship of this article.

\section{References}

1. Afifi AK, Bergman RA: Mesencephalon (midbrain). In: Functional Neuroanatomy, Text and Atlas, pp. 129-149. McGrawHill, New York, NY, 2005.

2. Afifi AK, Bergman RA: Special senses. In: Functional Neuroanatomy, Text and Atlas, pp. 309-315. McGraw-Hill, New York, NY, 2005.

3. Baeten LA, Powers BE, Jewell JE, Spraker TR, Miller MW: A natural case of chronic wasting disease in free-ranging moose (Alces alces shirasi). J Wildl Dis 43:309-314, 2007.

4. Bradley R: BSE transmission studies with particular reference to blood. Dev Biol Stand 99:35-40, 1999.

5. Cormack DH: The eye and the ear. In: Ham's Histology, 9th ed., pp. 679-698. JB Lippincott Co, Philadelphia, PA, 1987.

6. Fox KA, Jewell JE, Williams ES, Miller MW: Patterns of PrPCWD accumulation during the course of chronic wasting disease infection in orally inoculated mule deer (Odocoileus hemionus). J Gen Virol 87:3451-3461, 2006.

7. Greenlee JJ, Hamir AN, West-Greenlee MH: Abnormal prion accumulation associated with retinal pathology in experimentally inoculated scrapie-affected sheep. Vet Pathol 43:733-739, 2006.

8. Hamir AN, Gidlewski T, Spraker TR, Miller JM, Creekmore L, Crocheck M, Cline T, O'Rourke KI: Preliminary observations 
of genetic susceptibility of elk (Cervus elaphus nelsoni) to chronic wasting disease by experimental oral inoculation. J Vet Diagn Invest 18:110-114, 2006.

9. Hamir AN, Richt JA, Miller JM, Kunkle RA, Hall SM, Nicholson EM, O'Rourke KI, Greenlee JJ, Williams ES: Experimental transmission of chronic wasting disease of elk (Cervus elaphus nelsoni), white-tailed deer (Odocoileus virginianus) and mule deer (Odocileus hemionus hemionus) to white-tailed deer by intracerebral route. Vet Path 3:288-306, 2008.

10. Head WM, Northcott V, Rennison K, Ritchie D, McCardle L, Bunn TJ, McLennan NF, Ironside JW, Tullo AB, Bonshek RE: Prion protein accumulation in eyes of patients with sporadic and variant Creutzfeldt-Jakob disease. Invest Ophthalmol Vis Sci 44:342-346, 2003.

11. Herms J, Tings T, Gall S, Madlung A, Giese A, Siebert H, Schurmann P, Windl O, Brose N, Kretzschmar H: Evidence of presynaptic location and function of the prion protein. J Neurosci 19:8866-8875, 1999.

12. Hortells P, Monzon M, Monleon E, Acin C, Vargas A, Bolea R, Lujan L, Badiola JJ. Pathological findings in retina and visual pathways associated to natural scrapie in sheep. Brain Res 1108:188-194, 2006.

13. Humason GL: Animal Tissue Techniques, 3rd ed. WH Freeman Co, San Francisco, CA, 1972.

14. Jeffrey M, Martin S, Thomson JR, Dingwall WS, Begara-McGorum I, Gonzalez L: Onset and distribution of tissue PrP accumulation in scrapie-affected Suffolk sheep demonstrated by sequential necropsies and tonsilar biopsies. J Comp Pathol 125:48-57, 2001.

15. Junqueira LC, Carneiro J, Kelley RO: The sense organs. In: Basic Histology, 7th ed., pp. 470-487. Appleton \& Lange Co, Norwalk, CT, 1987.

16. Keane DP, Barr DJ, Bochsler PN, Bochsler PN, Hall SM, Gidlewski TE, O'Rourke KI, Spraker TR, Samuel MD: Chronic wasting disease in a Wisconsin captive white-tailed deer farm. J Vet Diagn Invest 20:698-703, 2008.

17. Kercher L, Favara C, Chan CC, Race R, Chesebro B: Differences in scrapie-induced pathology of the and brain in transgenic mice that express hamster prion protein in neurons, astrocytes, or multiple cell types. Am J Pathol 165:2055-2067, 2004.

18. Kercher L, Favara C, Striebel JF, LaCasse R, Chesebro B: Prion protein expression differences in microglia and astroglia influnce scrapie-induced neurodegeneration in the retina and brain of transgenic mice. J Virol 81:10340-10351, 2007.

19. Mead S, Poulter M, Uphill J, Beck J, Whitfield J, Webb TE, Campbell T, Adamson G, Deriziotis P, Tabrizi SJ, Hummerich $\mathrm{H}$, Verzilli C, Alpers MP, Whittaker JC, Collinge J: Genetic risk factors for variant Creutzfeldt-Jakob disease: a genome-wide association study. Lancet Neurol 8:57-66, 2009.

20. Moya KL, Sales N, Hassig R, Creminon C, Grassi J, Di Giamberardino L: Immunolocalization of the cellular prion protein in normal brain. Microsc Res Tech 50:58-65, 2000.

21. O'Rourke KI, Baszler TV, Besser TE, Miller JM, Cutlip RC, Wells GAH, Ryder SJ., Parish SM, Hamir AN, Cockett NE, Jenny A, Knowles DP: Preclinical diagnosis of scrapie by immunohistochemistry of third eyelid lymphoid tissue. J Clin Microbiol 38:3254-3259, 2000.
22. O'Rourke KI, Besser TE, Miller MW, Cline TF, Spraker TR, Jenny AL, Wild MA, Zebarth GL, Williams ES: PrP genotype of captive and free-ranging Rocky Mountain elk (Cervus elaphus nelsoni) with chronic wasting disease. J Gen Virol 80:2765-2679, 1999.

23. O'Rourke KI, Spraker TR, Zhuang D, Greenlee JJ, Gidlewski TE: Elk with a long incubation prion disease phenotype have a unique PrPd profile. Neuroreport 18:1935-8, 2007.

24. Perucchini M, Griffin K, Miller MW, Goldmann W: PrP genotyping of free-ranging wapiti (Cervus elaphus nelsoni) with chronic wasting disease. J Gen Virol 89:1324-1328, 2008.

25. Russelakis-Carneiro M, Hetz C, Maundrell K, Soto C: Prion replication alters the distribution of synaptophysin and caveolin 1 in neuronal lipid rafts. Am J Pathol 165:1839-1848, 2004.

26. Russell RWR: Visual pathways. In: Concise Oxford Textbook of Medicine, ed. Ledingham JG, Warrell, DA, pp. 1249-1252. Oxford University Press, New York, NY, 2000.

27. Sigurdson CJ, Spraker TR, Miller MW, Oesch B, Hoover EA: $\operatorname{PrP}(\mathrm{CWD})$ in the myenteric plexus, vagosympathetic trunk and endocrine glands of deer with chronic wasting disease. J Gen Virol 82:2327-2334, 2001.

28. Smith JD, Greenlee JJ, Hamir AN, West-Greenlee MH: Retinal cell types are differentially affected in sheep with scrapie. J Comp Pathol 138:12-22, 2008.

29. Sheehan DC, Hrapchak B: Theory and Practice of Histotechnology, 2nd ed., pp. 138-148. Mosby Co, St. Louis, MO, 1980.

30. Spraker TR, Balachandran A, Zhuang D, O'Rourke KI: Variable patterns of PrP-CWD distribution in obex and cranial lymphoid tissues of Rocky Mountain elk with nonclinical chronic wasting disease. Vet Rec 155:295-302, 2004.

31. Spraker TR, Gidlewski TL, Balachandran A, VerCauteren KC, Creekmore L, Munger RD: Detection of $\mathrm{PrP}^{\mathrm{CWD}}$ in postmortem rectal lymphoid tissues in Rocky Mountain elk (Cervus elaphus nelsoni) infected with chronic wasting disease. J Vet Diagn Invest 18:553-557, 2006.

32. Spraker TR, Miller MW, Williams ES, Getzy DM, Adrian WJ, Schoonveld GG, Spowart RA, O'Rourke KI, Miller JM, Merz PA: Spongiform encephalopathy in free-ranging mule deer (Odocoileus hemionus), white-tailed deer (Odocoileus virginianus) and Rocky Mountain elk (Cervus elaphus nelsoni) in north central Colorado. J Wildl Dis 33:1-6, 1997.

33. Spraker TR, O'Rourke KI, Balachandran A, Zink RR, Cummings BA, Miller MW, Powers BE: Validation of monoclonal antibody F99/97.6.1 for immunohistochemical staining of brain and tonsil in mule deer (Odocoileus hemionus) with chronic wasting disease. J Vet Diagn Invest 14:3-7, 2002.

34. Spraker TR, VanCauteren KC, Gidlewski TL, Balachandran A, Munger RD, O'Rourke KI: Antemortem detection of $\mathrm{PrP}^{\mathrm{CWD}}$ in preclinical, ranch-raised Rocky Mountain elk (Cervus elaphus nelsoni) by biopsy of the rectal mucosa. J Vet Diagn Invest 21:15-24, 2009.

35. Spraker TR, Zink RR, Cummings BA, Sigurdson CJ, Miller MW, O'Rourke KI: Distribution of protease-resistant prion protein and spongiform encephalopathy in free-ranging mule deer (Odocoileus hemionus) with chronic wasting disease. Vet Pathol 39:546-556, 2002. 
36. Thuring CM, Erkens JH, Jacobs JG, Bossers A, Van Keulen LJ, Garssen GJ, Van Zijderveld FG, Ryder SJ, Groschup MH, Sweeney T, Langeveld JP: Discrimination between scrapie and bovine spongiform encephalopathy in sheep by molecular size, immunoreactivity, and glycoprofile of prion protein. J Clin Microbiol 42:972-980, 2004.
37. Williams ES, Young S: Chronic wasting disease of captive mule deer: a spongiform encephalopathy. J Wildl Dis 16:89-98, 1980.

38. Williams ES, Young S: Spongiform encephalopathy of Rocky Mountain elk. J Wildl Dis 18:465-471, 1982.

39. Yoshikawa, T: Atlas of the Brain of Domestic Animals, pp. S1-S23, G1-G22. University of Tokyo Press, Tokyo, Japan, 1968. 